\title{
ULTRAFILTRATION OF PROTEIN SOLUTIONS; THE ROLE OF PROTEIN ASSOCIATION IN REJECTION AND OSMOTIC PRESSURE
}

\section{G.B. VAN DEN BERG*, J.H. HANEMAAIJER**}

Netherlands Institute for Dairy Research (NIZO), P.O. Box 20,6710 BA Ede (The Netherlands)

and C.A. SMOLDERS

Department of Chemical Technology, Twente University of Technology, P.O. Box 217, 7500 AE Enschede (The Netherlands)

(Received March 27, 1986; accepted in revised form December 8, 1986)

\section{Summary}

The monomer-dimer equilibrium of the protein $\beta$-lactoglobulin under neutral conditions appears to influence the rejection and the osmotic pressure build-up, both phenomena closely related to ultrafiltration. Rejection measurements indicate different rejections for the $\beta$-lactoglobulin monomers and dimers: the membrane rejects the dimer almost completely and the monomer only partially. The osmotic pressure turns out to be highly dependent on the protein concentration. A good agreement, up to high concentrations, is found between experimental data and theoretical osmotic pressures, calculated by taking into account the state of association, the excluded volume and the Donnan effects. The effect of changes in $\mathrm{pH}$ on the osmotic pressure has been measured: a minimum was found around $\mathrm{pH}=4.5$, where according to the literature, maximum protein-protein interaction occurs.

\section{Introduction}

During the past few decades whey, a liquid produced when milk is processed into cheese or casein, has developed from dairy waste into a valuable dairy product. In particular the whey proteins and lactose are valuable components of whey, and the isolation and the purification of the protein fraction has gained particular interest. Whey protein concentrates (WPC) can be made in various compositions, depending on the process used, with a wide range of nutritional and functional properties [1]. The major component of the whey proteins is the protein $\beta$-lactoglobulin.

*This work, carried out at NIZO, was part of the first author's study for his degree in Chemical Technology at the Twente University of Technology, which is his present address.

**'To whom correspondence should be addressed. 
One of the methods of processing whey is by ultrafiltration. An important aspect of ultrafiltration is the protein rejection, which is influenced by both membrane and solute characteristics. In the case of a solute such as $\beta$-lactoglobulin, which shows a concentration-dependent association, different rejections may be expected for the different states of association. Osmotic-pressure measurements may give information on the association equilibria of $\beta$-lactoglobulin under ultrafiltration conditions.

The osmotic pressure is also related to ultrafiltration in another way: in addition to solute adsorption, pore blocking etc., the permeate flux is limited by the difference in the osmotic value of the solutions on each side of the membrane. The osmotic pressure difference $\Delta \Pi$, which is further increased by concentration polarization at the membrane surface, decreases the flux by decreasing the effectiveness of the applied trans-membrane pressure $[2,3,4]$. The objectives of this paper are:

- to present osmotic-pressure data, measured under actual ultrafiltration process conditions, for the associating protein $\beta$-lactoglobulin;

- to explain these data by considering protein association, excluded volume and Donnan effects; and

- to show the relation between protein association and rejection.

\section{Theory}

\section{The association of $\beta$-lactoglobulin [5]}

Several genetic variant of the protein $\beta$-lactoglobulin exist, each with slightly different properties. Variants A and B are present in milk and whey obtained from Frisian cows. The protein tends to form oligomers, mostly dimers and some octamers, while other $n$-mers are present in negligible amounts. These oligomer formations seem to be the result of non-covalent bonds, which are probably based on hydrophobic interactions. Normally these interactions are maximal around the iso-electric point, which for $\beta$-lactoglobulin is at $\mathrm{pH}=5.2$. Both at lower and higher $\mathrm{pH}$-values (until $\mathrm{pH} \approx 8$, above which denaturation occurs) the state of association changes to form more monomers, fewer dimers and far fewer octamers.

This state of association of $\beta$-lactoglobulin has been the subject of extensive research [6-11]. Although the influence of several parameters such as $\mathrm{pH}$, ionic environment, concentration and temperature has been investigated, no data were available for practical (ultrafiltration) use. Georges et al. [6] gave monomer-dimer equilibrium constants $\left(K_{\text {eq }}\right)$ for several combinations of $\mathrm{pH}$ and temperature, obtained from light-scattering measurements. For $\mathrm{pH}=6.6$ and $T=323 \mathrm{~K}$ a value of $K_{\text {eq }}\left(=\left(C_{\text {monomers }}\right)^{2} / C_{\text {dimers }}\right)$ can be obtained from their data by interpolation: $K_{\mathrm{eq}}=2.90 \times 10^{-5} \mathrm{~mol}^{-1}$. Using this equilibrium constant the percentage of $\beta$-lactoglobulin dimers in solution can be calculated as a function of the total concentration. This dependence of the state of asso- 


\section{TABLE 1}

Equilibrium constants for two genetic variants of $\beta$-lactoglobulin at different temperatures and $\mathrm{pH}$ (ionic strength $I=0.1 \mathrm{~N}$ )

\begin{tabular}{lllcll}
\hline $\begin{array}{l}\text { Genetic } \\
\text { variant }\end{array}$ & $\begin{array}{l}T \\
(\mathrm{~K})\end{array}$ & $\mathrm{pH}$ & $\begin{array}{c}K_{\mathrm{eq}} \times 10^{6} \\
(\mathrm{~mol} / \mathrm{l})\end{array}$ & Technique & Ref. \\
\hline $\mathrm{C}$ & 293 & 2.5 & 95 & sedimentation & {$[9]$} \\
$\mathrm{C}$ & 293 & 4.7 & 0.52 & sedimentation & {$[8]$} \\
B & 293 & 2.6 & 160 & sedimentation & {$[10]$} \\
B & 293 & 2.7 & 51 & light scattering & {$[11]$} \\
B & 293 & 7.0 & 5.6 & light scattering & {$[6]$} \\
B & 313 & 7.0 & 30 & light scattering & {$[6]$} \\
B & 333 & 7.0 & 129 & light scattering & {$[6]$} \\
\hline
\end{tabular}

ciation of $\beta$-lactoglobulin on the solute concentration will be used in the equations below.

The state of association of $\beta$-lactoglobulin appears to depend not only on concentration but also on temperature and $\mathrm{pH}$. In Table 1 the association equilibrium constants for $\beta$-lactoglobulin $\mathrm{B}$ and $\mathrm{C}$ are given, as found by several investigators. They are summarized as a function of temperature, $\mathrm{pH}$ and method of determining the equilibrium constant. The ionic strength $I$ is $0.1 \mathrm{~N}$ in all cases.

In Fig. 1 the dependence of the fraction of dimers of $\beta$-lactoglobulin $\mathrm{B}$ on temperature and concentration is given. The fraction of dimers clearly declines with increasing temperature.

To compare the monomer-dimer equilibrium of the $\mathrm{B}$ and the $\mathrm{C}$ variant at the same $\mathrm{pH}$, equilibrium constants of several investigators were used, each using different measuring techniques. Though the data do not match exactly, the calculated fraction of dimers seems to be roughly the same (curves a, b and $\mathrm{c}$ in Fig. 2). Also, the method of determining the equilibrium constant seems of little importance.

In Fig. 2 the fraction of dimers of the two variants of $\beta$-lactoglobulin ( $\mathrm{B}$ and $\mathrm{C}$ ) is also given as a function of $\mathrm{pH}$ and concentration at $293 \mathrm{~K}$ and $I=0.1 \mathrm{~N}$, making use of the listed $K_{\text {eq }}$ values. To illustrate solely the monomer-dimer equilibrium at different $\mathrm{pH}$-values, $\beta$-lactoglobulin $\mathrm{C}$ was used at the iso-electric point, because the $C$ variant is the only variant which is unable to form oligomers larger than dimers, such as octamers, at $\mathrm{pH}$-values around the isoelectric point [5]. Now the fraction of dimers increases with increasing $\mathrm{pH}$, when going from $\mathrm{pH}=2.6$ to $\mathrm{pH}=4.7$, and decreases again when the $\mathrm{pH}$ increases further to $\mathrm{pH}=7.0$. This corresponds with the decreasing charge of $\beta$-lactoglobulin when changing the $\mathrm{pH}$ from 2.6 to about 5 and increasing charge at higher $\mathrm{pH}$ values [12]. 
$\mathrm{C}_{\text {dimers }} / \mathrm{C}_{\text {total }}$ (weight fraction)

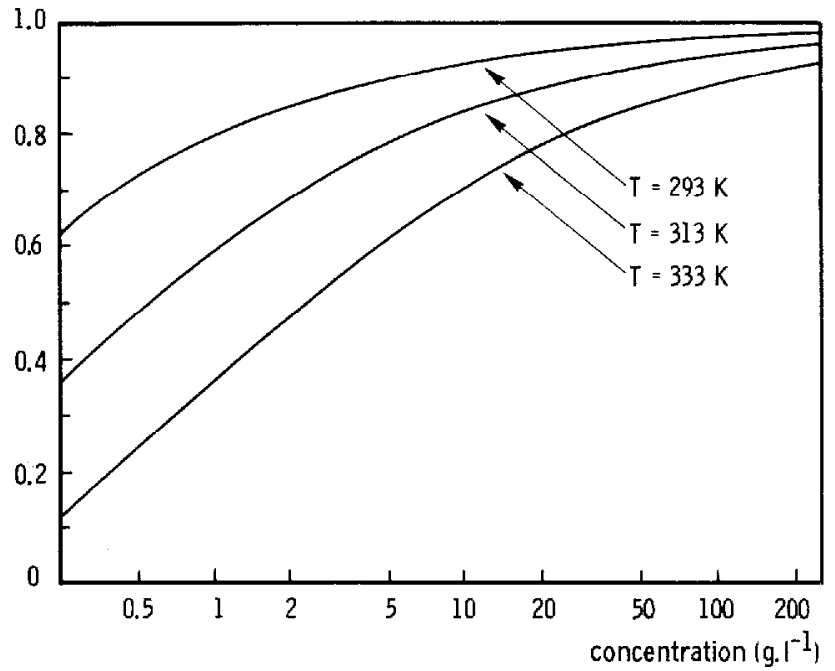

Fig. 1. The fraction of dimers of $\beta$-lactoglobulin $\mathrm{B}$ as a function of temperature and concentration $(\mathrm{pH}=7.0$ and $I=0.1 \mathrm{~N})$.

\section{Rejection in ultrafiltration}

The rejection of a solute in protein ultrafiltration, at constant pressure, is known to be dependent on membrane type (pore size and pore distribution),

\section{$\mathrm{C}_{\text {dimers }} / \mathrm{C}_{\text {total }}$ (weight fraction)}

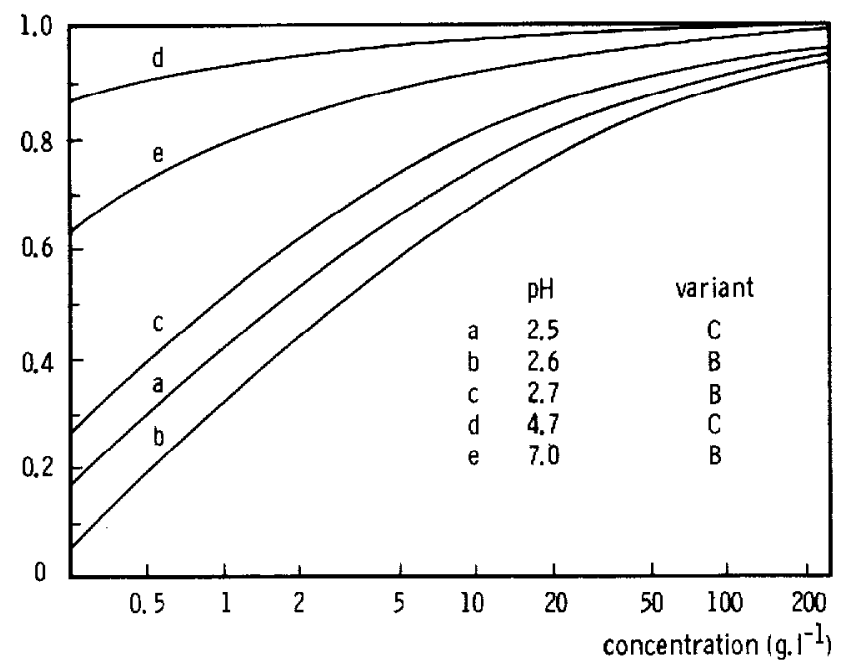

Fig. 2. The fraction of dimers of $\beta$-lactoglobulin $\mathrm{B}$ and $\mathrm{C}$ as a function of $\mathrm{pH}$ and concentration $(T=293 \mathrm{~K}$ and $I=0.1 N)$. Equilibrium constants from literature (see Table 1). 
on solute adsorption [13] and the presence of a concentration polarization and gel layer [14].

The rejection as observed in an experiment is defined as:

$R=1-\left(C_{\mathrm{p}} / C_{\mathrm{c}}\right)$

where $C_{\mathrm{p}}$ is the concentration of the permeate $\left(\mathrm{g}-\mathrm{l}^{-1}\right)$ and $C_{\mathrm{c}}$ is the concentration of the (bulk) concentrate $\left(\mathrm{g}^{-\mathrm{l}^{-1}}\right)$. In fact, the true rejection should be calculated from the concentration at the membrane interface, which is much higher than the bulk concentration because of concentration polarization. This interfacial concentration cannot be measured directly. The state of association of $\beta$-lactoglobulin will add one more variable to the set of parameters which determine the overall rejection value $R$, because protein association can be expected to increase the protein rejection.

\section{Osmotic pressure}

Several relations have been proposed to describe the osmotic pressure of macromolecular solutions at different concentrations $[4,15,16]$. The basic thermodynamic equation for non-ideal solutions is (e.g. Ref. [17]):

$$
\pi=\frac{R T}{M}\left(C+B_{2} C^{2}+B_{3} C^{3}+\ldots\right) \quad(\mathrm{Pa})
$$

in which the virial coefficients $B_{2}\left(1-\mathrm{g}^{-1}\right)$ and $B_{3}\left(\mathrm{l}^{2}-\mathrm{g}^{-2}\right)$ can be calculated as a function of several parameters, such as the excluded volume, the hydration and the Donnan effects.

In this work we shall calculate the osmotic pressure to a certain extent like Vilker et al. [18] have proposed: the osmotic pressure is calculated taking into account the ideal Donnan effects (the first term in eqn. 3 ) and the excluded volume (the second term in eqn. 3 ):

$$
\pi=10^{3} R T\left[2 \sqrt{(Z C / 2 M)^{2}+I^{2}}-2 I\right]+\frac{R T}{M}\left(C+B_{2}{ }^{\mathrm{ev}} C^{2}+B_{3}{ }^{\mathrm{ev}} C^{3}\right)
$$

where $Z$ is the net charge of the proteins and $I$ is the ionic strength of the protein solution. To calculate the Donnan-effect term we shall use $Z=-12$ and $M=35,500$, as found by Basch and Timasheff [12] at $\mathrm{pH}=6.6$. The value of $Z=-12$ is an average for $\beta$-lactoglobulin A and B. The Donnan effects will, of course, be calculated by using the total protein concentration.

The excluded volume-based virial coefficients $B_{2}{ }^{\text {ev }}$ and $B_{3}{ }^{\text {ev }}$ will be calculated as functions of the molecular volume $v_{\mathrm{m}}\left(\mathrm{m}^{3}\right)$ and the shape-dependent parameters $R_{1}(\mathrm{~m})$ and $S_{1}\left(\mathrm{~m}^{3}\right)$ [19]:

$$
\begin{aligned}
& B_{2}{ }^{\mathrm{ev}}=\left(v_{\mathrm{m}}+R_{1} S_{1}\right)\left(10^{3} N_{\mathrm{av}} / M\right) \\
& B_{3}{ }^{\mathrm{ev}}=\left[\left(v_{\mathrm{m}}\right)^{2}+2 R_{1} S_{1} v_{\mathrm{m}}+\frac{1}{3}\left(R_{1} S_{1}\right)^{2}\right]\left(10^{3} N_{\mathrm{av}} / M\right)^{2}
\end{aligned}
$$


TABLE 2

Shape-dependent parameter equations used to determine the virial coefficients $B_{2}^{\text {ev }}$ and $B_{3}^{\text {ev }}$

\begin{tabular}{lll}
\hline & For spheres & For cylinders \\
\hline$v_{\mathrm{m}}$ & $\frac{4}{3} \pi r^{3}$ & $\pi r^{2} l$ \\
$R_{\mathrm{j}}$ & $r$ & $(l+r) / 4$ \\
$S_{1}$ & $4 \pi r^{2}$ & $2 \pi r(l+r)$ \\
\hline
\end{tabular}

where $N_{\text {av }}$ is Avogadro's number.

To calculate $v_{\mathrm{m}}, R_{1}$ and $S_{1}$ we have made use of the fact that the $\beta$-lactoglobulin monomer is a globular protein, while dimeric $\beta$-lactoglobulin is rod-like [15]. For the monomer $r=1.8 \mathrm{~nm}$ is used and for the cylindrical dimer $r=1.8$ $\mathrm{nm}$ and $l=7.2 \mathrm{~nm}[5]$. Table 2 shows the equations necessary to calculate the viral coefficients. Based on eqn. $(3), \pi_{\text {(total) }}$ can be calculated according to

$\pi_{(\text {total })}=\pi_{(\text {monomers })}^{\mathrm{ev}}+\pi_{(\text {dimers })}^{\mathrm{ev}}+\pi_{\mathrm{D}(\text { mixture })} \quad(\mathrm{Pa})$

where $\pi^{\mathrm{ev}}$ (monomers) and $\pi^{\mathrm{ev}}$ (dimers) are the excluded volume terms of the osmotic pressure of the monomers and the dimers, respectively, and $\pi_{D}$ is the Donnaneffect term on the osmotic pressure using the total concentration of the mixture.

\section{Determination of the state of association by reduced osmotic-pressure measurements}

The reduced osmotic pressure $(\pi / C)$ can give more information about the state of association of $\beta$-lactoglobulin. When the reduced osmotic pressure $(\pi / C)$ is plotted versus the concentration, according to Van't Hoff's law, the molecular weight $M$ can be determined by extrapolating $\pi / C$ to $C=0$ (i.e., when an ideal situation is approached), then:

$\pi / C \lim _{C \rightarrow 0}=R T / M \quad\left(\mathrm{~Pa}-\mathrm{l}-\mathrm{g}^{-1}\right)$

Or reversed, when the molecular weight is known, the state of association of $\beta$-lactoglobulin can be deduced. For $\beta$-lactoglobulin: $\pi / C=146.7 \mathrm{~Pa}-1-\mathrm{g}^{-1}$ for monomers with $M=18,300$ and $\pi / C=73.3 \mathrm{~Pa}-\mathrm{l}^{-\mathrm{g}^{-1}}$ for dimers with $M=36,600$.

The value for the reduced osmotic pressure of a mixture of monomeric and dimeric protein molecules can easily be derived, knowing the contributions of both the monomers and the dimers and the Donnan effects for the entire mixture:

$$
(\pi / C)_{\text {mixture }}=\frac{\left(\pi^{\mathrm{ev}}{ }_{\text {(monomers })}+\pi^{\mathrm{ev}}{ }_{(\text {dimers })}+\pi_{\mathrm{D}}\right)}{C_{\text {monomers }}+C_{\text {dimers }}} \quad\left(\mathrm{Pa}-1-\mathrm{g}^{-1}\right)
$$




\section{Materials and methods}

\section{1. $\beta$-lactoglobulin}

The $\beta$-lactoglobulin was isolated at NIZO from casein whey. After desalting, clarification [20], ultra- and diafiltration, the whey protein mixture was fractionated on a Pharmacia Stack KS370/15 pilot-plant column, using DEAE Sepharose Fast Flow anion exchanger. The pure fractions were concentrated by ultrafiltration and freeze-dried.

Protein solutions were made by dissolving the $\beta$-lactoglobulin in a Jenness and Koops buffer $(I=0.1 N)$ of the desired $\mathrm{pH}$ [21]. Adjustments were made by adding $0.1 \mathrm{~N} \mathrm{HCl}$ or $0.1 \mathrm{~N} \mathrm{NaOH}$ to the solutions.

The water used was distilled and pre-filtered using a reverse-osmosis membrane module (Nitto NTR 7250).

\section{Osmotic pressure measurements}

The osmotic pressure as a function of concentration and solution $\mathrm{pH}$ was determined using a high-pressure osmometer [22], thermostatted at $50.0 \pm 0.5^{\circ} \mathrm{C}$. This osmometer is capable of measuring osmotic pressures larger than $0.5 \mathrm{kPa}$.

Both Abcor HFK-131 membranes ( $M_{\mathrm{w}}$ cut-off 5000 , rejection $99.9+\%$ for $\beta$-lactoglobulin) and Amicon Diaflo UM-30 membranes ( $M_{\mathrm{w}}$ cut-off 30,000 with $99+\%$ rejection for $\beta$-lactoglobulin) were used in the osmometer. In order to obtain information on the influence of $\mathrm{pH}$, osmotic pressure measurements were performed at $323 \mathrm{~K}$ with solutions at various $\mathrm{pH}$ and concentrations of $100 \mathrm{~g}^{-1}{ }^{-1}$.

\section{Rejection measurements and ultrafiltration experiments}

The ultrafiltration experiments were performed with an Amicon TCF-10A thin channel cell. The experimental conditions were: $T=323 \mathrm{~K}, \Delta P=150 \mathrm{kPa}$ and tangential flow velocity $v=1.63 \mathrm{~m}$ - $\mathrm{sec}^{-1}$. The membrane used was a Rhone Poulenc Iris 3038 membrane $\left(M_{\mathrm{w}}\right.$ cut-off 30,000$)$.

\section{Analytical procedures}

The concentration of the $\beta$-lactoglobulin solutions, used for the osmoticpressure experiments, was determined chemically by the Kjeldahl method [23]. As a control the $\beta$-lactoglobulin concentration of the solution at the solvent side of the osmometer was also determined.

To determine the concentration during ultrafiltration of both the concentrate and the permeate (very low concentrations), and also to control the purity of the protein, high-performance gel permeation chromatography (HP-GPC) was used. The column used was a Dupont GF250 column, the detection wavelength was $280 \mathrm{~nm}$ and the buffer: $0.1 \mathrm{~mol}^{-1}$ potassium phosphate $/ 0.15 \mathrm{~mol}$ $\mathrm{I}^{-1}$ sodium phosphate at $\mathrm{pH}=6.0$; the flow rate was $1.0 \mathrm{ml}-\mathrm{min}^{-1}$. 


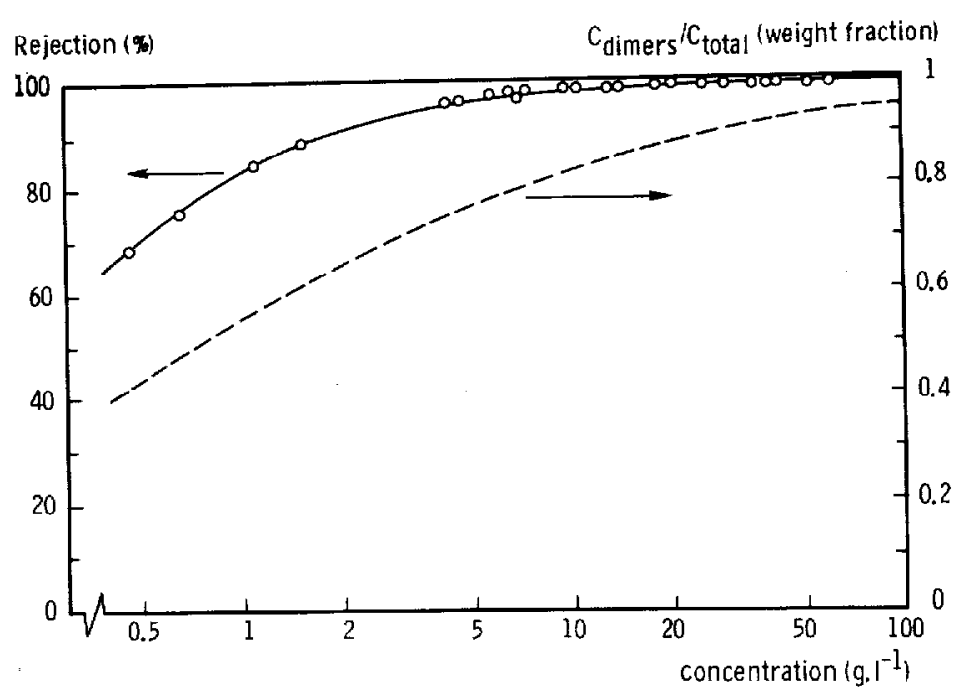

Fig. 3. Solid curve: rejection of $\beta$-lactoglobulin as a function of feed concentration (Iris 3038 membrane, $\mathrm{pH}=6.6, T=323 \mathrm{~K}$ and $I=0.1 \mathrm{~N}$ ). Dashed curve: fraction of dimers at the same conditions.

\section{Results and discussion}

\section{Rejection}

From seven independent, batch-wise performed ultrafiltration experiments a number of rejection data were gathered at different degrees of concentration. Each experiment was performed with a new Iris 3038 membrane. This resulted in the rejection as a function of the concentration as plotted in Fig. 3. Because all data points are situated on one curve, even though starting concentrations ranging from 0.1 to $4.0 \mathrm{~g}-\mathrm{l}^{-1}$ were used, it can be concluded that any shifts in association equilibria do not influence the rejection significantly. For comparison the fraction of dimers at the experimental conditions (using $K_{\text {eq }}=2.90 \times 10^{-5} \mathrm{~mol}^{-l^{-1}}$ ) is given by the dashed line.

The rejection increases clearly with the protein concentration of the retentate. This may also be predicted from the increasing fraction of dimers, resulting from the monomer-dimer equilibrium of $\beta$-lactoglobulin. The rejection of the dimers will be higher than the rejection of the smaller monomers, so the total rejection will increase. Though knowing the quantities of monomers and dimers and the total rejection, the exact rejection of both the monomers and the dimers cannot be calculated yet. The explanation must probably be found in additional phenomena which play a role in protein rejection during ultrafiltration: partitioning of solute in the pore entrance area, solute adsorption, pore blocking and eventually the formation of a gel layer. These phenomena 
osmotic pressure $(\mathrm{kPa}$

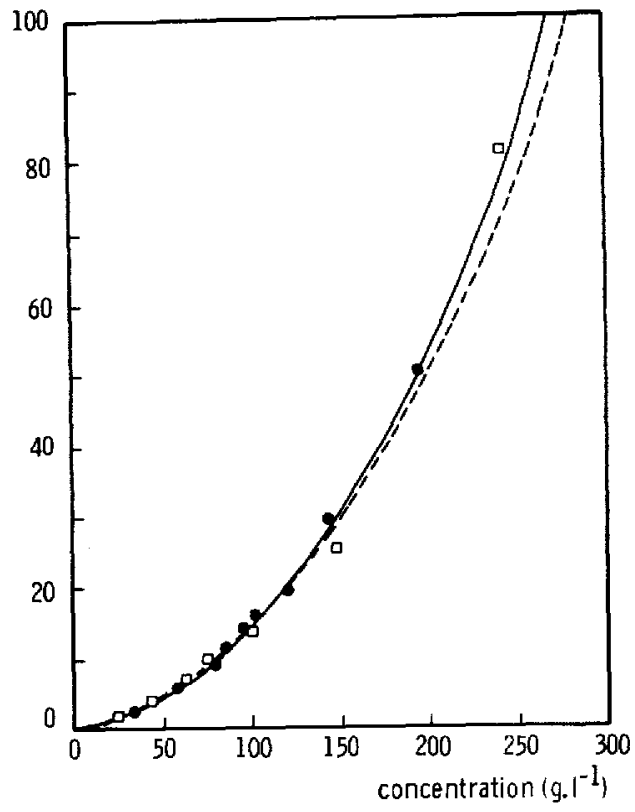

Fig. 4. The osmotic pressure of $\beta$-lactoglobulin as a function of concentration $(\mathrm{pH}=6.6, T=323$ $\mathrm{K}$ and $I=0.1 \mathrm{~N}$ ). Solid curve: measured osmotic pressures (eqn. 10); the membranes used were ( $\square$ ) Amicon Diaflo UM 30 and ( ) Abcor HFK131. Dashed curve: calculated osmotic pressures (eqn. 3).

are functions of time, protein concentration and the membrane characteristics, which are quite complex altogether and have not been exactly under control until now.

When, at the start of an experiment and at very low concentrations, the rejection is measured, it appears that this rejection is higher than could be expected from rejection of dimers only. At this point the above-mentioned additional phenomena will be of minor influence, so that the rejection of monomers will be higher than zero. For instance a rejection of ca. $50 \%$ for monomers and $100 \%$ for dimers at initial conditions (low concentrations, no proteins adsorbing or pore blocking) can explain the initial overall rejection quite well. At higher concentrations the rejection then increases as a result of the phenomena mentioned above.

\section{The osmotic pressure of $\beta$-lactoglobulin}

Results of osmotic-pressure measurements using both the HFK 131 membrane and the UM 30 membrane are reported in Fig. 4. The small permeability for $\beta$-lactoglobulin when using the UM 30 membrane did not seem to effect the measurements. The maximum concentration at the "pure-solvent" side was $0.5{\mathrm{~g}-\mathrm{I}^{-1}}^{-1}$ wich results in a (very small) osmotic pressure of about $40 \mathrm{~Pa}$. 
Curve fitting of the data by a non-linear least-squares method resulted in:

$$
\pi=79.4 C+0.419 C^{2}+0.0025 C^{3} \quad(\mathrm{~Pa})
$$

where $C$ is in $\mathrm{g}^{-1^{-1}}$. Though there is a small difference between the experimental osmotic pressures (the drawn curve in Fig. 4) and theoretical values based on the theoretical model (the dashed curve in Fig. 4), we think the agreement is remarkable. Thus, using simple theoretical equations, the osmotic pressure can be predicted rather accurately, even at higher concentrations. At high concentrations, such as appear at the membrane during ultrafiltration, the osmotic pressure can reach rather high values, e.g. $\pi \approx 85 \mathrm{kPa}$ at $250 \mathrm{~g}-\mathrm{l}^{-1}$ and $\pi \approx 260$

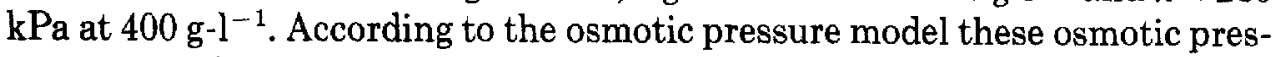
sures will reduce the driving force $(\Delta P-\Delta \pi)$ considerably, resulting in much lower product fluxes.

\section{The state of association of $\beta$-lactoglobulin}

In Fig. 5 the reduced osmotic pressure is plotted against the concentration. The drawn line is derived from the curve-fit equation (eqn. 10). Extrapolation to $C=0$ yields a value of $79.4 \mathrm{~Pa}-1-\mathrm{g}^{-1}$. This value approaches the value of 73.3 $\mathrm{Pa}-\mathrm{l}-\mathrm{g}^{-1}$ for dimers quite well, so that from these osmotic-pressure measurements it can be concluded that $\beta$-lactoglobulin, at the concentrations used, mainly consists of dimers.

Because osmotic pressures were measured only of solutions with moderately high to very high concentrations, this conclusion corresponds with the calculations made before. From data on the equilibrium constant it was shown that at low concentrations the $\beta$-lactoglobulin mainly consists of monomers. This seems to contradict the experiments, where $\beta$-lactoglobulin seems to consists only of dimers, and therefore the theoretical reduced osmotic pressures were also calculated using eqn. (8). The result is the dashed curve in Fig. 5. Starting from the value of $\pi / C=146.7 \mathrm{~Pa}-\mathrm{l}-\mathrm{g}^{-1}$ for monomers, according to Van't Hoff's law, the reduced osmotic pressure decreases rapidly, reaches a minimum at a rather low protein concentration and increases again.

\section{The influence of $\mathrm{pH}$ on the osmotic pressure}

In Fig. 6 a comparison is given of the osmotic pressure, measured at various $\mathrm{pH}$ values, with the expected osmotic pressure at $\mathrm{pH}=6.6$. A minimum was found around $\mathrm{pH}=4.5$. It should be noticed that this region is not the locus of the $\beta$-lactoglobulin iso-electric point, which is at 5.2. However, this minimum corresponds with the minimum $(\mathrm{pH}=4.40-4.65)$ in free enthalpy of the association reaction, derived from sedimentation and light-scattering experiments $[7,24]$, resulting in maximal protein-protein interactions in this region.

At both lower and higher $\mathrm{pH}$ the osmotic pressure increases quite symmetrically around $\mathrm{pH}=4.5$, suggesting a relation with the degree of protein asso- 
reduced osmotic pressure $\left(\mathrm{Pa} . \mathrm{I.g} \mathrm{g}^{-\mathrm{l}}\right)$

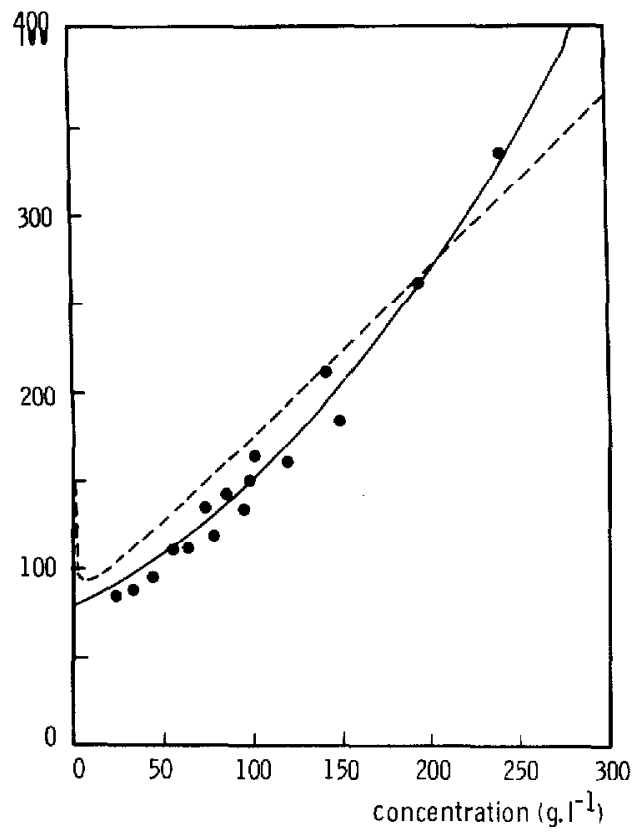

Fig. 5. The reduced osmotic pressure of $\beta$-lactoglobulin as a function of concentration $(\mathrm{pH}=6.6$, $T=323 \mathrm{~K}, I=0.1 \mathrm{~N}$ ). Solid curve: experimental curve, using eqn. (10). Dashed curve: theoretical curve, using eqn. (8).

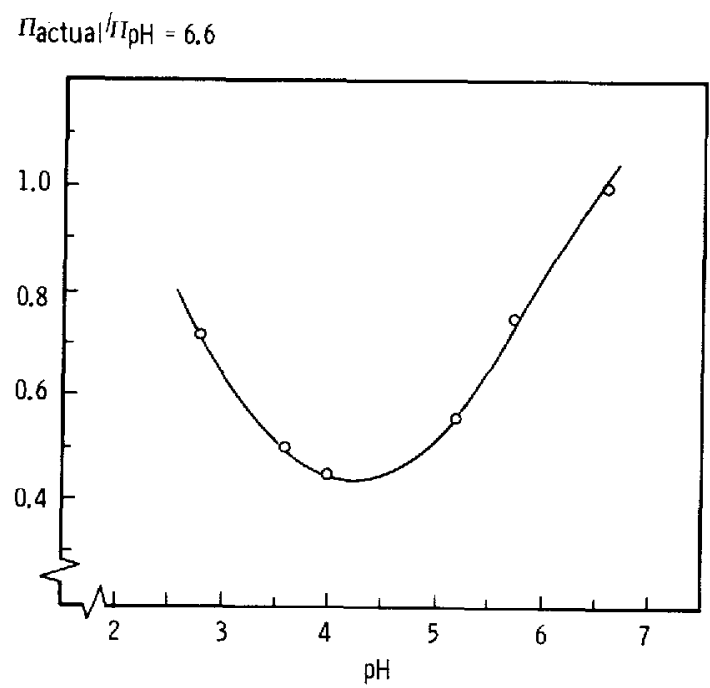

Fig. 6. The osmotic pressure of $\beta$-lactoglobulin as a function of $\mathrm{pH}$ (concentration $=100 \mathrm{~g}-\mathrm{1}^{-1}$, $T=323 \mathrm{~K}$ and $I=0.1 \mathrm{~N}$ ). 
ciation. At $\mathrm{pH}$ values much higher than $6.6 \beta$-lactoglobulin will readily denature and therefore this high $\mathrm{pH}$ region was not investigated.

\section{Conclusions}

During ultrafiltration of $\beta$-lactoglobulin solutions both protein rejection and osmotic pressure are influenced by the state of association of the protein.

The increasing rejection with the protein concentration appears to be related to the increasing degree of protein association, although not exclusively. Probably other phenomena, such as solute adsorption and pore blocking, also increase the rejection.

The osmotic-pressure data support the data on the association of $\beta$-lactoglobulin derived from the literature. Under common process conditions during ultrafiltration of sweet whey ( $T=323 \mathrm{~K}, \mathrm{pH}=6.6)$, most of the $\beta$-lactoglobulin is present as dimers. During ultrafiltration of acid whey $(T=323 \mathrm{~K}$, $\mathrm{pH}=4.5$ ) oligomerization probably takes place.

Taking protein association, the excluded volume and Donnan effects into account, the osmotic pressure at various concentrations and process conditions can be predicted rather well.

Especially during ultrafiltration of sweet whey when high concentrations occur at the membrane surface, considerable contributions of the osmotic pressure to limitation of the flux must be expected.

\section{Acknowledgements}

We would like to thank Mr. G. Klarenbeek for preparing the $\beta$-lactoglobulin samples, Mr. C. Brons for performing the HP-GPC analyses and Ms. Acda, Ms. W. Versluis and Mr. J. Leenders for performing the numerous additional analyses.

\section{List of symbols}

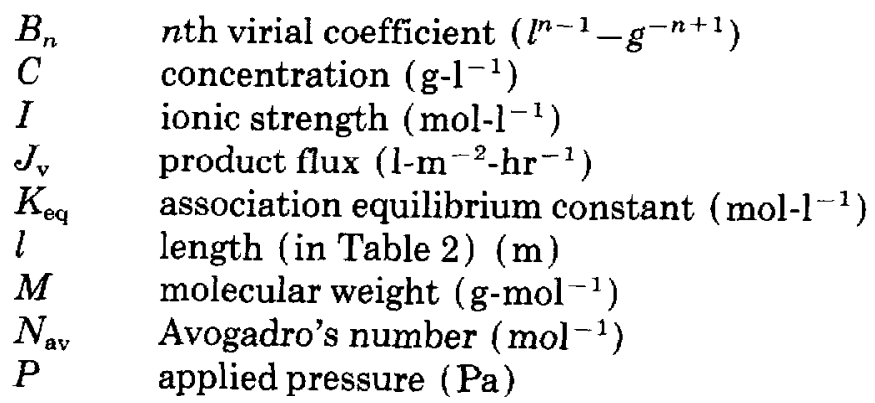




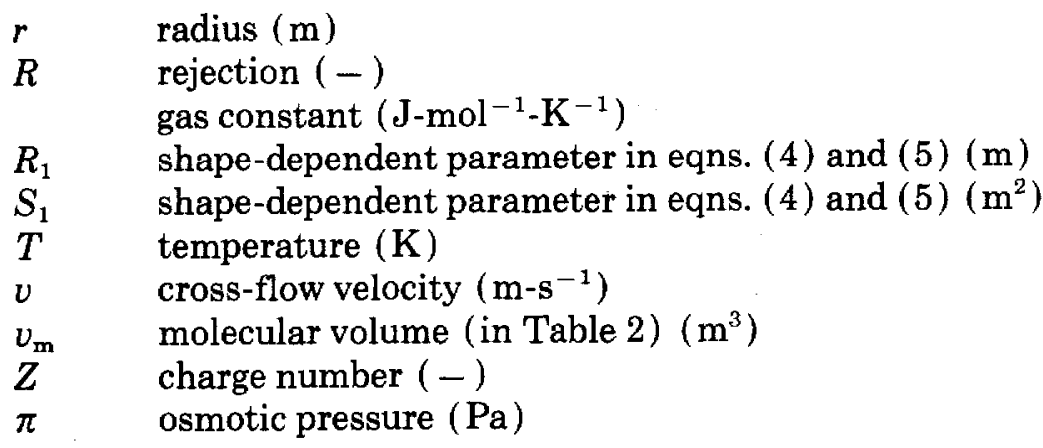

\section{Subscripts}

$\begin{array}{ll}\text { c } & \text { (bulk) concentrate } \\ \text { D } & \text { Donnan effect } \\ \text { P } & \text { permeate }\end{array}$

Superscript

ev excluded volume

\section{References}

1 J.N. de Wit, Functional properties of whey proteins in food systems, Neth. Milk Dairy J., 38(1984) 71-89.

2 J.G. Wijmans, S. Nakao and C.A. Smolders, Flux limitation in ultrafiltration: osmotic pressure model and gel layer model. J. Membrane Sci., 20 (1984) 115-128.

3 R.L. Goldsmith, Macromolecular ultrafiltration with microporous membranes, Ind. Eng. Chem., Fundam., 10 (1971) 113-120.

4 V.L. Vilker, C.K. Colton, K.A. Smith and D.L. Green, The osmotic pressure of concentrated protein and lipoprotein solutions and its significance to ultrafiltration, J. Membrane Sci., 20 (1984) 63-77.

5 H.A. McKenzie, in: H.A. McKenzie (Ed.), Milk Proteins, Chemistry and Molecular Biology, Vol. II, Academic Press, New York, NY, 1971.

6 C. Georges, S. Guinand and J. Tonnelat, Étude thermodynamique de la dissociation de la $\beta$ lactoglobuline $\mathrm{B}$ pour pH supérieurs à 5.5, Biochim. Biophys. Acta, 59 (1962) 737-739.

7 R. Townend and S.N. Timasheff, The $\mathrm{pH}$ dependence of the association of $\beta$-lactoglobulin, Arch. Biochem. Biophys., 63 (1956) 482-484.

8 J.L. Sarquis and E.T. Adams, Self-association of $\beta$-lactoglobulin $C$ in acetate buffers, Biophys. Chem., 4 (1976) 181-190.

9 J.L. Sarquis and E.T. Adams, The temperature-dependent self-association of $\beta$-lactoglobulin C in glycine buffers, Arch. Biochem. Bioph., 163 (1974) 442-452.

10 D.A. Albright and J.W. Williams, A study of the combined sedimentation and chemical equilibrium of $\beta$-lactoglobulin in acid solution, Biochemistry, 7 (1968) 67-78.

11 S.N. Timasheff and R. Townend, Molecular interactions in $\beta$-lactoglobulin. V. The association of the genetic species of $\beta$-lactoglobulin below the iso-electric point, J. Amer. Chem. Soc., 83 (1961) 464-476. 
12 J.J. Basch and S.N. Timasheff, Hydrogen ion equilibria of the genetic variants of bovine $\beta$ lactoglobulin, Arch. Biochem. Biophys., 118 (1967) 37-47.

13 L.J. Zeman, Adsorption effects in rejection of macromolecules by ultrafiltration membranes, J. Membrane Sci., 15 (1983) 213-230.

14 S. Nakao and S. Kimura, Effect of gel layer on rejection and fractionation of different molecular-weight solutes by ultrafiltration, in: A.F. Turbak (Ed.), Synthetic Membranes, Vol. II, ACS Symp. Ser. 154, American Chemical Society, Washington, DC, 1981, pp. 119-132.

15 P.G. de Gennes, Scaling Concepts in Polymer Physics, Cornell University Press, Ithaca, NY, 1979.

16 P.J. Flory, Principles of Polymer Chemistry, Cornell University Press, Ithaca, NY, 1953.

17 M.P. Tombs and A.R. Peacock, The Osmotic Pressure of Biological Macromolecules, Clarendon Press, London, 1974.

18 V.L. Vilker, C.K. Colton and K.A. Smith, The osmotic pressure of concentrated protein solutions: effect of concentration and $\mathrm{pH}$ in saline solutions of bovine serum albumin, J. Colloid Interface Sci., 79 (1981) 548-566.

19 J.R. Barker and D. Henderson, What is liquid? Understanding the states of matter, Rev. Mod. Phys., 48 (1976) 587-671.

20 J.N. de Wit, G. Klarenbeek and R. de Boer, A simple method for the clarification of whey, Proc. 20th Int. Dairy Congr., Paris, 1978, pp. 919-920.

21 R. Jenness and J. Koops, Preparation and properties of a salt solution which simulates milk ultrafiltration, Neth. Milk Dairy J., 16 (1962) 153.

22 F.W. Altena, Phase separation phenomena in cellulose acetate solutions in relation to asymmetric membrane formation, Ph.D. Thesis, Twente University of Technology, Enschede, 1982.

23 International Standard FIL-IDF 20, Determination of the total nitrogen content of milk by the Kjeldahl method, Int. Dairy Federation, 1962.

24 R. Townend and S.N. Timasheff, Molecular interactions in $\beta$-lactoglobulin. III. Light scattering investigation of the stoichiometry of the association between $\mathrm{pH} 3.7$ and 5.2, J. Amer. Chem. Soc., 82 (1960) 3168-3174. 